\title{
Derecho de falar, derecho de existir
}

Right to Speak, Right to Exist

\author{
Yarlenis Ileinis Mestre Malfrán \\ Mara Coelho de Souza Lago
}

\section{$-2$}

RIBEIRO, Djamila.

O que é lugar de fala?

Belo Horizonte: Letramento, 2017.

La accesibilidad al conocimiento es un argumento de peso para sustentar la urgencia de ciertas lecturas como las de O que é lugar de fala?'. En el libro, la autora comienza justamente por declarar una de las motivaciones para producirlo: "traer para el gran público asuntos importantes referidos a los más diversos feminismos de forma didáctica y accesible"2 (Djamila RIBEIRO, 2017, p. 13, traducción nuestra). El volumen asume entonces el compromiso político de distanciarse de la sofisticación intelectual, que es muchas veces la estrategia de un proyecto colonial que se sirve del leguaje como un instrumento de poder. En tal sentido, quebrar las barreras que han sido impuestas a sujetos impedidos de acceder a los procesos de educación es una apuesta y un mérito de este libro, que por demás no renuncia a asumir una reflexión teórica importante.

Hemos optado por mantener en esta reseña el término - falar - tan importante para la reflexión propuesta, así como el concepto central que se aborda en el libro: lugar de fala, en el idioma en el que él fue teorizado, por considerar que la traducción de lugar de fala, equivalente en español a lugar de habla o lugar de enunciación, tal vez no tendría inteligibilidad para los hispanohablantes, una vez que estas expresiones son infrecuentes en castellano. Más allá de eso, la traducción literal podría traer varias complicaciones. Una de ellas sería la de asociar el término lugar apenas con geografía y el concepto traduce mucho más que eso, al tiempo que no desconoce la geografía como un punto importante de conformación de la experiencia. También pudiera caerse en el equívoco de relacionar hablar con el mero acto de emitir palabras. La traducción literal correría el riesgo de un reduccionismo que negaría la potencia de este concepto, que apunta sobre todo a una ubicación en el conjunto de las relaciones sociales que son, siempre, relaciones de poder. Lugar de fala, pensado en la lógica de Adrienne Rich (1987), apuntaría para un lugar en que el sujeto es creado y también tiene capacidad de crear, un lugar que habla de geografía, pero también de historia, un territorio que no solo debe ser pensado en su sentido más abarcador (¿desde qué continente estoy ubicada para pensar como pienso?) sino en su sentido

\footnotetext{
${ }^{1}$ El presente trabajo fue realizado con el apoyo de: Coordenação de Aperfeiçoamento de Pessoal de Nível Superior - Brasil (CAPES) - Código de Financiamiento - 001.

2 En el original: "trazer para o grande público questões importantes referentes aos mais diversos feminismos de forma didática e acessível" (RIBEIRO, 2017, p. 13).
} 
más próximo; es decir, el territorio del cuerpo que habitamos y que es un cuerpo generificado, racializado, sexualizado, con una edad y tantos otros marcadores sociales que condicionan nuestro discurso y que permitirían entender el carácter localizado, situado, de esos discursos.

Formando parte de la colección Feminismos Plurais, con una extensión de 112 páginas divididas en cuatro secciones, el libro se inscribe precisamente dentro de las propuestas que traen otras epistemologías, provenientes de los saberes infravalorados, de las otredades que históricamente han sido expulsadas a los márgenes de la estructura social. Saberes que resisten y que invitan a otras posibilidades de existencia. Djamila Ribeiro, licenciada y Máster en Filosofía por la Universidad Federal de São Paulo, se encuadra entre las feministas que debaten temas relativos a la intersección de género y raza.

Inspirada en Ángela Davis (2016) y en tantas otras pensadoras negras con quien dialoga en su libro, la autora apuesta por un feminismo negro que contribuya a pensar y crear un proyecto de sociedad donde todas/os puedan existir. Siendo coherente con esa pretensión, el libro cumple cabalmente dos propósitos: divulgar un conjunto de ideas emanadas de la producción intelectual de mujeres negras a quien Djamila recurre para construir su narrativa; y traer a debate la multiplicidad y complejidad de las opresiones que delinean la existencia de mujeres negras.

A partir del desafío de comprender las particularidades de las opresiones experimentadas por mujeres negras, es que se justifica la necesidad de marcar el lugar de enunciación. Djamila Ribeiro es contundente en su tesis acerca de las implicaciones de lugar de fala, cuando expone lo que este concepto denota:

El hablar no se restringe al acto de emitir palabras, sino de poder existir. Pensamos lugar de fala como la posibilidad de refutar la historiografía tradicional y la jerarquización de saberes derivada de la jerarquización social. Cuando hablamos de derecho a la existencia digna, a la voz, estamos hablando de locus social, de cómo ese lugar impuesto dificulta la posibilidad de trascendencia. En lo absoluto eso tiene que ver con una visión esencialista de que solamente el negro puede hablar de racismo, por ejemplo (RIBEIRO, 2017, p. 64, traducción nuestra) ${ }^{3}$.

Fiel a ese propósito la autora comienza el libro con la sección titulada "Un poco de historia", para mostrarnos por medio de la emblemática figura de Sojouner Truth (2014) que el feminismo negro no es moda, ni apenas comenzó recientemente, sino que muy por el contrario, las trayectorias de lucha y de resistencia de mujeres negras, simbolizadas en el histórico discurso de Sojourner Truth: - ¿Acaso yo no soy una mujer $?^{4}-$, han desafiado las representaciones hegemónicas que han circunscrito lo femenino a la experiencia de mujeres blancas de clase media.

En este mismo apartado del libro, Djamila explica el alcance de esa invisibilización. En ese recontar la historia, la autora recupera algunas de las ideas de bell hoks (2013), Audre Lorde (2013) y Lélia González (1984), para explicar cómo uno de los efectos del racismo ha sido la desautorización epistémica de las mujeres negras. En tal sentido el feminismo europeo, como marco teórico privilegiado para dar cuenta de las opresiones de las mujeres, se tornó cómplice de una cierta manera occidental de hacer ciencia, de ahí que solo pudiera abarcar un campo bien limitado de reivindicaciones que solo decían de la existencia de algunas mujeres. Todo ello justifica la opción de Djamila por un feminismo afro latinoamericano, cuestión que retoma de Lélia González (1984), para apuntar la necesidad de desestabilizar regímenes discursivos propios de epistemologías dominantes.

Operar una ruptura en las autorizaciones discursivas que solo tornan audibles y visibles las experiencias de algunos sujetos, es la opción política de un feminismo negro. Dentro de esa epistemología feminista negra, el concepto de lugar de fala, implica detenerse en la categoría de mujer negra y lo que ella vendría a aportar al análisis pretendido. Un posible cuestionamiento gira en torno de icómo contribuye esa categoría - mujer negra - a reflexionar acerca de las desigualdades creadas por el modo en que el poder articula esa posición social que entrecruza género y raza?

De hecho, la autora expone la recurrencia de las acusaciones que tildan al feminismo negro de esencialista, identitario y consecuentemente sectario. Inclusive, una de las cuestiones que pudieran objetarse a la argumentación de Djamila Ribeiro, es el no reconocer la proximidad del concepto que ella sistematiza en este libro con las formulaciones de Adrienne Rich (1987) sobre las políticas de localización o de saberes localizados de Donna Haraway (1995). Lugar de fala trae en sí el eco de las reflexiones de estas dos autoras, aunque no es desde ellas que Djamila construye su argumentación.

\footnotetext{
${ }^{3}$ En el original: "O falar não se restringe ao ato de emitir palavras, mas de poder existir. Pensamos lugar de fala como refutar a historiografia tradicional e hierarquização de saberes consequente da hierarquia social. Quando falamos de direito à existência digna, à voz, estamos falando de locus social, de como esse lugar imposto dificulta a possibilidade de transcendência. Absolutamente não tem a ver com uma visão essencialista de que somente o negro pode falar sobre racismo, por exemplo" (RIBEIRO, 2017, p. 64).

${ }^{4}$ Originalmente el discurso es "Ain't I a Woman?" e foi traduzido pelo Doutor Osmundo Pinho, da Universidade Federal do Recôncavo da Bahia.
} 
De todas formas, no deja de ser una opción legítima, privilegiar las contribuciones de autoras negras para trazar la trayectoria de este concepto, cuyos referentes ella delinea en esta primera parte del libro. La postura de Djamila Ribeiro, para sustentar su recorte, se expresa en este planteamiento: "vamos a entender por qué muchas feministas negras pensaron la categoría de mujer negra. Estas reflexiones nos van a ayudar a entender lugar de fala"5 (RIBEIRO, 2017, p. 31, traducción nuestra).

Habiendo esclarecido entonces que hay un recorte específico (feminismo negro) a partir del cual se está construyendo un raciocinio, en la segunda sección del libro, la autora toma como punto de partida la categoría de lo Otro, acuñada por Simone de Beauvoir (1980), para explicar la insuficiencia de dicha categoría al no ser capaz de revelar el doble vacío que supone no ser nombrada ni dentro del género - mujeres negras son menos que mujeres - ni dentro de la raza negra que apela o dice del hombre negro, no así de la mujer negra, la que vendría a configurarse como una otredad doblemente invisibilizada. De la mano de Grada Kilomba (2012), la autora explica el modo en que esa doble carencia hace necesaria la elaboración de la categoría mujer negra, en tanto condición para salir de un lugar de neutralidad que supone inexistencia.

Situado ese análisis, la autora nos hace dialogar con Patrícia Hill Collins (2016) para pensar en esa subalternidad por otro camino, y no apenas por el de la destitución de la condición de sujeto, sino aquel que apunta a desafiar la norma colonizadora. Es por medio del concepto de outsider within de Collins (2016) que se vislumbra, según la autora, la posibilidad de sacar provecho de ese lugar de los márgenes, como posición que ofrece otras lentes para observarse a sí mismas y al mundo, como lugar que ofrece perspectivas potentes de análisis acerca de las opresiones y privilegios, devenidas de las experiencias interseccionales de mujeres negras. A eso justamente remitiría el lugar de fala.

Por fin, el trayecto seguido por Djamila Ribeiro durante las dos primeras partes del libro, permite adentrarse en las especificidades del concepto lugar de fala, que constituye el penúltimo apartado. La primera advertencia que ayuda a ubicar a quien lee, es que se trata de un concepto de origen impreciso. Aunque autores como Michel Foucault (2012), Linda Alcoff (2016) o Gayatrik Spivak (2010) sean fundamentales en la emergencia de este concepto, la autora es categórica en su elección del punto de vista feminista negro, como marco para pensar el concepto. La elección está lejos de ser arbitraria, los dos primeros apartados del libro creemos que fundamentan esta elección. En todo caso, el punto de vista feminista negro, como teoría social crítica, es totalmente coherente con la pretensión de teorizar acerca de lugar de fala, por tratarse de una epistemología que se propone resistir a las ideologías y prácticas que estructuran múltiples opresiones.

El vicio académico por las definiciones concretas tal vez lleve a muchos a buscar el párrafo específico en que la autora expone una definición tácita acerca de lo que es lugar de fala. A nuestro juicio, es tanto una cuestión que se delimita como que se deja en abierto. Pensando en las delimitaciones del concepto que aparecen reflejadas en el libro, vale decir que el concepto apunta para un lugar social que se configura a partir de las complejas intersecciones entre raza, género, clase, sexualidad entre otros marcadores sociales que establecen lugares para grupos subalternizados.

En la comprensión de la autora, este operador teórico advierte de la necesidad de atender a las condiciones sociales que estructuran los lugares que esos grupos ocupan en las sociedades, y el modo en que ellos posibilitan o impiden el acceso a la ciudadanía. Lugar de fala significa reconocimiento en la matriz de inteligibilidad de la ciudadanía, posibilidad de existencia y por ende de instituirse como sujeto de derechos en un contexto de democracia.

La discusión acerca de lugar de fala, destaca Djamila Ribeiro, no tiene que ver con identidades esencializadas, sino con denunciar la existencia de una matriz de opresión que, al ser visibilizada, se opone a los discursos totalizadores que hablan por todos y en nombre de un todos que excluye a algunos/as, por no decir que a muchos/as. Las cifras del encarcelamiento de la población negra y del feminicidio en Brasil complementan este argumento de la autora.

En el último apartado del libro, el título de la sección asevera: "TODO EL MUNDO TIENE LUGAR $D E F A L{ }^{\prime \prime}$. No obstante, deberíamos sospechar de tal afirmación, porque si bien es cierto que todas/os tienen posibilidades de enunciación, las reflexiones esbozadas por la autora a lo largo del libro revelan los mecanismos que se yerguen para impedir que algunos/as sean escuchados/ as, visibilizados/as, humanizados/as, por tanto, que existan. El libro termina precisamente respondiendo a los ataques y críticas que con frecuencia alcanzan al concepto, y que bien pudieran ser pensados como estrategias que impiden el avance de estas narrativas. La autora sintetiza la resistencia que opera el concepto frente a esas invisibilidades, con la frase de Lélia González (1984) que inaugura el texto: "la basura va a hablar, y va a hablar en serio"7 (RIBEIRO,

\footnotetext{
${ }^{5}$ En el original: "Agora vamos a entender o porquê muitas feministas negras pensaram a categoria mulher negra. Essas reflexões vão nos ajudar a entender lugar de fala" (RIBEIRO, 2017, p. 31).

'En el original: "TODO MUNDO TEM LUGAR DE FALA" (RIBEIRO, 2017, p. 81)

7 En el original: "o lixo vai falar, e numa boa". (RIBEIRO, 2017, p. 90).
} 
2017, p. 90, traducción nuestra).

\section{Referências}

ALCOFF, Linda. "Uma epistemologia para a próxima revolução". Revista Sociedade e Estado, [online] v. 31, n. 1, p. 129-143, jan./abr. 2016.

BEAUVOIR, Simone. O segundo sexo: a experiência vivida. Tradução de Sérgio Millet. São Paulo: Difusão Europeia do Livro, 1980.

COLLINS, Patricia Hill. "Aprendendo com a outsider within: a significação sociológica do pensamento feminista negro". Revista Sociedade e Estado, [online] Brasília, v. 31, n. 1, p. 99-127, 2016.

DAVIS, Ângela. Mulheres, Raça e Classe. Tradução de Heci Regina Candiani. São Paulo: Boitempo, 2016.

FOUCAULT, Michel. A ordem do discurso. Tradução de Laura Fraga de Almeida Sampaio. São Paulo: Edições Loyola, 2012.

GONZÁLEZ, Lélia. "Racismo e sexismo na cultura brasileira". Revista Ciências Sociais Hoje [online], Anpocs, p. 233-244, 1984, Disponible en: http://goo.gl/VFdjdq. Acceso el: 04/09/2018.

HARAWAY, Donna. "Saberes localizados: a questão da ciência para o feminismo e o privilégio da perspectiva parcial”. Cadernos Pagu, n. 5, p. 07-41, 1995.

hooks, bell. Ensinando a transgredir: a educação como prática de liberdade. Tradução de Ana Luiza Libânio. São Paulo: Martins Fontes, 2013.

KILOMBA, Grada. Plantation Memories: Episodes of Everyday Racism. 2. ed. Münster: UNRAST-Verlag, 2010.

LORDE, Audre. "Mulheres negras: As ferramentas do mestre nunca irão desmantelas a casa do mestre". Tradução de Renata. Geledés [online], São Paulo, 10/07/2013. Disponible en: https:// www.geledes.org.br/mulheres-negras-as-ferramentas-do-mestre-nunca-irao-desmantelar-a-casado-mestre/. Acceso el 04/09/2018.

$\mathrm{RICH}$, Adrienne. "Notes Towards a Politics of Location". In: RICH, Adrienne. Blood, Bread and Poetry: Selected Prose 1979-85. London: Virago, 1987, p. 210-231.

SPIVAK, Gayatri. Pode o subalterno falar? Tradução de Sandra Regina Goulart Almeida, Marcos Pereira Feitosa, André Pereira Feitosa. Belo Horizonte: Editora UFMG, 2010.

TRUTH, Sojourner. "E não sou uma mulher?" Tradução de Osmundo Pinho. Geledés, São Paulo, 8 jan. 2014. Disponible en: https://www.geledes.org.br/e-nao-sou-uma-mulher-sojourner-truth/. Acceso el: $04 / 09 / 2018$.

Yarlenis lleinis Mestre Malfrán (iD) 0000-0003-1923-481 1

Doutoranda no Programa de Pós-Graduação Interdisciplinar em Ciências Humanas da Universidade Federal da Santa Catarina

Possui graduação em Psicologia pela Universidade de Oriente, Santiago de Cuba (1999), mestrado em Intervenção Comunitária pelo Instituto Superior de Ciências Médicas Habana/Cuba (2004). Professora e pesquisadora no Departamento de Psicologia da Universidad de Oriente (2003-2017). Professora convidada do Instituto de Estudos Superiores "Isidoro da Graça" de São Vicente (atualmente Universidade do Mindelo), Cabo Verde, de 2005-2007. Tem experiência na área de Psicologia, especificamente no campo dos Estudos de Gênero. Pesquisa políticas públicas de saúde em Cuba sob a lente analítica da interseccionalidade. Bolsista PEC-PG/CAPES (201 7-2021). Universidade Federal de Santa Catarina, Programa de Pós-Graduação Interdisciplinar em Ciências Humanas

R. Eng. Agronômico Andrei Cristian Ferreira, s/n, Trindade

88040-900 - Florianópolis - SC - Brasil

+55 (48) 3721-9320-gr@contato.ufsc.br

yarlenis.mestre@ufsc.br 
Mara Coelho de Souza Lago (iD) 0000-0001-5111-8699

Doutorado em Psicologia da Educação pela Universidade Estadual de Campinas (UNICAMP) Como Professora Titular aposentada do Departamento de Psicologia da Universidade Federal de Santa Catarina, instituição que a agraciou com o título de Professora Emérita, atua na qualidade de Professora Voluntária, nos quadros de docentes permanentes dos Programas de Pós-Graduação em Psicologia (PPGP/UFSC) e Pós-Graduação Interdisciplinar em Ciências Humanas (PPGICH/UFSC). Participa da coordenação do Núcleo de Pesquisa Modos de Vida, Família e Relações de Gênero (MARGENS/PSI/UFSC) e do Instituto de Estudos de Gênero (IEG/UFSC). Seus interesses de pesquisa e docência se relacionam a questões de gênero, psicologia social e interdisciplinaridade, com publicações de livro, coletâneas e artigos voltados a esses campos de conhecimentos.

Universidade Federal de Santa Catarina, Programa de Pós-Graduação Interdisciplinar em Ciências Humanas

R. Eng. Agronômico Andrei Cristian Ferreira, s/n, Trindade

88040-900 - Florianópolis - SC - Brasil

+55(48) 3721-9320,gr@contato.ufsc.br

maralago7@gmail.com

\section{COMO CITAR ESSE ARTIGO DE ACORDO COM AS NORMAS DA REVISTA}

MESTRE MALRÁN; Yarlenis lleinis; LAGO, Mara Coelho de Souza. "Derecho de falar, derecho de existir". Revista Estudos Feministas, Florianópolis, v. 27, n. 1, e59599, 2019.

\section{CONTRIBUIÇÃO DE AUTORIA}

Yarlenis lleinis Mestre Malrán - Concepção e elaboração do manuscrito; revisão e aprovação da versão final do trabalho

Mara Coelho de Souza Lago - Concepção e elaboração do manuscrito; revisão e aprovação da versão final do trabalho

\section{FINANCIAMENTO}

Coordenação de Aperfeiçoamento de Pessoal de Nível Superior - Brasil (CAPES) - Código de Financiamiento - 001

\section{CONSENTIMENTO DE USO DE IMAGEM}

Não se aplica

APROVAÇÃO DE COMITÊ DE ÉTICA EM PESQUISA

Não se aplica

\section{CONFLITO DE INTERESSES}

Não se aplica

\section{LICENÇA DE USO}

Este artigo está licenciado sob a Licença Creative Commons CC-BY. Com essa licença você pode compartilhar, adaptar, criar para qualquer fim, desde que atribua a autoria da obra.

\section{HISTÓRICO}

Recebido em 04/10/2018

Aprovado em 24/1 1/2018 